\title{
A METRÓPOLE SOB A PERSPECTIVA DA ALIENAÇÃO E DA APROPRIAÇÃO DE ESPAÇOS: INCURSÕES PELO CENTRO ANTIGO DE SÃO PAULO ${ }^{1}$
}

\author{
Ulysses Cunha Baggio²
}

Resumo: $O$ artigo se propõe a uma análise da metrópole sob a perspectiva da alienação e da apropriação de espaços, tomando-se como referência empírica a cidade de São Paulo e, mais especificamente, o seu centro antigo. Destacam-se ações e práticas sociais que sugerem contrapontos à mortificação do espaço, sinalizando a apropriações possíveis.

Palavras-chave: alienação socioespacial; apropriação de espaços; vida cotidiana; centro antigo de São Paulo.

The metropolis under the perspective of alienation and the appropriation of spaces: incursions by the old center of São Paulo

\begin{abstract}
The article proposes an analysis of the metropolis from the perspective of alienation and appropriation of spaces, taking as reference the empirical city of São Paulo, and more specifically, your old center. Stand out actions and social practices that suggest counterpoints to the mortification of space, signaling the possible allocations.
\end{abstract}

Keywords: alienation sociospatial; appropriation of spaces; everyday life; old center of São Paulo

\section{INTRODUÇÃO E ABORDAGEM METODOLÓGICA}

O texto em tela deriva de uma relação afetiva com a cidade de São Paulo, especialmente o seu Centro Antigo, que reputamos ser o verdadeiro núcleo identitário e coração vivo da metrópole paulistana. E já não é de hoje que palmilhamos as suas calçadas e nos incursionamos por seus interstícios, permitindo-nos permear múltiplas ambiências e situações.

O texto enfatiza a análise da apropriação social de lugares e da alienação do espaço, com foco empírico na metrópole paulistana, mais especificamente lugares de sua área central.

A sua realização reflete um desejo permanente e uma paixão pelos estudos sobre a cidade e o urbano na contemporaneidade, especialmente a metrópole, apresentando-se em sintonia com as possibilidades abertas pela dinâmica contraditória de produção do espaço, no encalço de manifestações, expressões residuais, forças resistentes e/ou insurgentes que possam sinalizar ou representar virtualidades importantes à vida urbana e ao conhecimento da própria cidade em sua

\footnotetext{
${ }^{1}$ Este artigo, com modificações, resulta de nossa pesquisa de pós-doutorado realizada junto ao Programa de Pós-Graduação em Geografia Humana do Departamento de Geografia da Universidade de São Paulo, entre março de 2012 a fevereiro de 2013, intitulada "Territorializações intersticiais da apropriação de espaços na metrópole paulistana: utopias urbanas do desejo libertário", sob a supervisão da Profa. Dra. Amélia Luisa Damiani.

${ }^{2}$ Professor e pesquisador do Departamento de Geografia da Universidade Federal de Viçosa.
} 
complexidade atual. Devotamos-nos, sobretudo, a lugares de uso coletivo, remetendo-nos, desse modo, a análises em torno da apropriação social de espaços, da formação de situações geográficas e, por contraste, do problema da alienação socioespacial e da fragmentação urbanometropolitana. Reavaliam-se, assim, os próprios significados e projeções desses lugares ao plano da vida cotidiana.

Mesmo com as grandes transformações que se processam na metrópole, envolvendo situações de deterioração e certa "decadência" em sua área central, nosso interesse e envolvimento não se arrefeceram em relação a essa parte da cidade. A cada incursão realizada, nos púnhamos em contato com lugares e expressões socioterritoriais os mais diversos, diante dos quais o olhar percorria as ruas e seus movimentos como páginas de um livro envolvente, com o espírito fluindo de modo a que nenhum desejo pudesse ser desperdiçado. Ruávamos por entre formas urbanas e incursionávamos por ambientes como uma necessidade existencial. E nenhum dia mostrava-se igual ao outro, e certos lugares, ainda que já conhecidos, se revelavam como "novos" lugares, com expressões não redundantes, inserindo-nos, assim, numa tessitura de situações e momentos da vida cotidiana que se renovam todo o tempo.

O trabalho de pesquisa de campo - de caráter marcadamente qualitativo -, se valeu de derivas e caminhadas exploratórias em dias e horários variados, com abordagens in loco mais específicas, diálogos abertos de caráter mais espontâneo, acrescidos de levantamento bibliográfico de interesse, sobretudo junto ao Arquivo Histórico de São Paulo. Percorremos calçadas de ruas e avenidas diversas, sobretudo do centro velho, feiras livres, bares, galerias, praças, calçadões, proximidades de cracolândias, hotéis, casas noturnas, galerias, shoppings centers, mercados, teatros, lojas, etc. Essa abordagem, efetivamente ao rés do chão, recobriu praticamente todo o período da pesquisa (março de 2012 a fevereiro de 2013), mas que, no entanto, começou antes disso, mais precisamente desde o ano de 2011, de forma mais sistemática e voltada aos propósitos de uma pesquisa, quando então elaborávamos o seu projeto. Não é demais dizer ainda que também nos valemos do fato, e da experiência, de termos residido no centro de São Paulo já há algum tempo, em torno de 1990, na Avenida Casper Líbero, bem próximo ao Viaduto Santa Ifigênia, durante quase oito meses. Ainda que tenha sido num período bem anterior ao de realização da pesquisa, permitiu-nos referências e conhecimentos valiosos sobre ele, aproveitados nessa empreitada. Portanto, trata-se de um espaço incorporado à nossa própria vida e existência. Intentamos, com isso, aproximações exploratórias em torno de modos e expressões de uso social coletivo, aferindo possibilidades em termos de apropriação e valorização simbólica, tendo-se em 
mente a dimensão controversa que envolve essa discussão. Ao mesmo tempo, levam-se em conta na análise interferências e determinações do processo mais atual do desenvolvimento da metrópole, com projetos e ações de revitalização em sua área central, reverberando na valorização econômica do espaço, nas relações sociais, na vida cotidiana e na morfologia urbana.

\section{Incursões pelos meandros da metrópole: a dimensão política do viver no espaço} contraditório

A objetivação do movimento de corrosão e degenerescência socioespacial avança, contraditoriamente, com a produção de resistências e insurgências, notadamente provenientes dos interstícios da cidade e da sociedade urbana, como atestam diversas práticas que vêm sendo conduzidas na cidade, que, de forma crescente, emergem sob os reclamos da necessidade e do desejo, que ainda se manifestam como valores vitais em meio ao nivelamento redutor que incide sobre eles. E por mais que os planejadores e urbanistas do Estado, bem como empreendedores e loteadores urbanos definam ou orientem a forma física urbana, e suas correlacionadas funções sendo a criação objetiva destas o limite de suas ações -, não se pode, contudo, controlar ou mesmo prever com eficácia as dinâmicas e expressões do processo social e o que efetivamente as pessoas pensam ou fazem.

Aqui intervém a dimensão política do viver e da existência, permitindo e estimulando tanto a crítica ao indesejável como a formulação de alguma forma ou estratégia de intervenção, que poderá até mesmo se realizar sob a forma de apropriação de espaços, conformando nos lugares modos relacionais dotados de certa especificidade, conferindo-lhes, assim, alguma particularidade, pela qual eles se tornam conhecidos e socialmente demandados, podendo-se qualificá-los como lugares ou formas territoriais de agregação e sociabilidade urbanas. Neles, o indivíduo e o individualismo tendem a perder-se sob o desejo da interação grupal em suas variadas expressões, ainda que efêmeras e descontínuas, não obstante efervescentes e capazes de se recomporem, irradiadas pelos interstícios do tecido metropolitano. Temos que elas compõem ambiências que sugerem uma inegável vontade de vida, embora recaiam sobre elas elementos restritivos ou mesmo de degeneração. As ambiências não se mostram, todavia, rígidas, sob um tempo não linear, havendo nelas certo estado de vacuidade que lhes possibilita pulsões criadoras e potencialidades. Nesse cenário socioterritorial de emergências de agregação social, derivas são práticas quase que habituais, dando-nos, assim, a idéia de uma espacialidade mundana sob as 
contradições e compressões da vida cotidiana. Sob estes aspectos elas comparecem mesmo como demandas existenciais, operando desvios à racionalidade coercitiva, de mal-estar. O "desvio", que recobre lugares, se mostraria, assim, algo próprio, se não inerente à própria vida cotidiana, sobretudo em modalidades coletivas, tanto em espaços abertos como fechados, sob as interferências de morfologias e espacialidades restritivas e coercitivas. Ele se estenderia assim ao plano das estratégias da vida cotidiana. De modo relacionado, a deriva, por sua vez, representa, pela perspectiva situacionista, uma forma de "comportamento experimental ligado às condições da sociedade urbana", podendo também ser compreendida como "uma técnica de passagem ativa através das ambiências variadas. Se diz também, mais particularmente, para designar a duração de um exercício contínuo desta experiência”. (IS, 1958)

Sob esse cenário socioespacial efervescente e plural, a idéia de possibilidade como horizonte factível a realização do desejo e da necessidade, se enreda no chão vivo e descontínuo como possibilidade real, ou ainda como utopia concreta, pois forjada a partir de uma base real, sob as condições do presente, afastando-se assim de visões idealistas e de uma postura meramente contemplativa da realidade. A utopia concreta se apresenta, portanto, como algo não fantasioso ou quimérico, não se pondo aos sentidos como uma mera derivação da imaginação humana, mas como algo lastreado na realidade e referenciado por ela, com potencialidades sensíveis à reestruturação da sociedade, o que solicita ações práticas na perspectiva de mudanças e transformações socialmente desejadas e necessárias. Não sem razão a utopia concreta encontrar na esperança o seu princípio ativo basilar, fundador, posto que:

\begin{abstract}
"A esperança é, pois, uma condição de toda a ação, visto que ela supõe ser possível fazer algo e diz que vale a pena fazê-lo em uma determinada situação. Para o homem experimentado, e mesmo para o favorecido pela sorte, pode tratar-se de algo mais do que esperança: a certeza daquele que confia em si mesmo. Mas, por maior que seja a confiança em si, só se poderia ter a esperança de que os desdobramentos daquilo que já se obteve será, no fluxo imprevisível das coisas, aquilo que se desejou"(JONAS, 2006, p.351).
\end{abstract}

Ernst Bloch ([1959] 2005), por sua vez, preconiza que a esperança (concreta) situa-se no limiar da insatisfação do homem diante de sua condição histórico-social, expressando-se, assim, como uma categoria política de emancipação social.

A busca pelo possível, numa realidade sob forte ideologização, que ofusca outros caminhos, pode até mesmo revelar-se sob as condições atuais como um caminho sinuoso, mas não como algo inescrutável, projetando-se como uma necessidade, uma urgência diante das banalizações, reducionismos e alienações que perpassam as relações sociais do presente e, desse modo, o 
espaço. Daí a necessidade de um exame atento e paciencioso sobre a cidade e o urbano, mais especificamente no que importa às possibilidades concretas abertas às formas de uso e apropriação social de lugares da cidade, sintonizadas com os desejos, anseios e demandas sociais, não raro e historicamente reprimidas e negadas pelo Estado.

Não sem razão essas formas irromperem no cotidiano sob o sentido da insurgência, suscitadas por necessidades que clamam, pela necessidade da existência e do existir, que encerram virtualidades à criação do novo e a transformação pluralista da sociedade. Como utopia concreta essas forças deixam de ser algo distante para inscrever-se nos interstícios da vida cotidiana como uma efetiva efervescência relacional, na qual os mais diversos elementos da natureza humana entram em sinergia, efervescência da qual somos, de um modo ou de outro, protagonistas, na qual o percurso, forjado contra e ao lado de adversidades sociais (como, p.ex. burocratização da vida social, violência, etc.) e institucionais (crise e inadequação de instituições em face de importantes problemas sociais objetivos), parece assumir maior importância que o próprio objetivo a atingir, sob a inconstância e a versatilidade política e ideológica das relações sociais.

Certas evidências na vida cotidiana de cidades latino-americanas e, mais especificamente, brasileiras, confirmariam, pela nossa compreensão, essa situação insurgente, irrequieta, que não necessariamente representa a negação do Estado ou de alguma forma de autoridade legitimada, embora em parte haja forças dotadas desse caráter, mas que no conjunto e acima de particularismos de contorno, grafam nos lugares e interstícios da cidade diferenças e caracteres indissociavelmente vinculados à promoção desigual e descontínua da vida, do humano, sinalizando luminosidades na urdidura urbana para além de um "mundo" de privações e reduções. Oferecem-se como exemplos, práticas artísticas e multiculturais nas periferias urbanas e em áreas centrais de São Paulo, Rio de Janeiro e Belo Horizonte, não raro recobrindo formas de uso e ocupação de lugares, como sinaliza, entre outros, o movimento hip hop e as práticas de rappers, multiplicando ações de encontro e associação, uso social e revalorização simbólica de lugares, conferindo aos seus atores e suas práticas culturais locais visibilidade pública e politização de seus dramas cotidianamente vividos, evidenciando demandas sociais e econômicas reprimidas, forjando, dentro de certos limites, respostas possíveis a elas; sistemas de produção alternativos e práticas de economia solidária, que se desenvolvem e ganham maior projeção no país e em outras partes do mundo, propiciando condições de vida mais favoráveis aos trabalhadores, com maior controle e interferência dos próprios interessados no processo produtivo e na distribuição dos ganhos auferidos; movimentos organizados de moradores em defesa e resguardo de acervo 
cultural e arquitetônico de bairros e modos de vida historicamente constituídos, oferecendo certos limites a processos especulativos e de destruição tanto de formas como de ambiências urbanas, que se projetam, não raro, como resistências e permanências na cidade submetida a vetores poderosos de apropriação, exploração e valorização econômica do espaço; usos coletivos e territorializados de lugares e formas construídas, tanto pelas chamadas "tribos urbanas" ou por outros grupos, que sinalizam para novas formas ou modalidades de sociabilidade na cidade; práticas coletivas propositivas de mobilidade urbana, podendo-se destacar as de mobilidade cicloviária, que avançam progressivamente em termos de organização e mobilização, influindo maior politização em torno dessa questão premente à vida urbana. Além destas pode-se ainda mencionar a criação de parques lineares em áreas degradadas (em aspectos diversos) da cidade, podendo-se torná-las espaços mais acessíveis à população, transformando-as em lugares de uso social aberto e coletivo. Não se defende aqui, com essa idéia, quaisquer operações que envolvam expropriações de moradores pobres, no sentido de um deslocamento da pobreza para outras áreas da cidade.

Não nos parece que essas práticas (que não se limitam a movimentos sociais, recobrindo também formas diversas de uso e intervenção coletiva nos lugares, de forma organizada ou espontânea) sejam tão residuais como por vezes se diz, podendo-se perceber mesmo o seu crescimento por lugares diversos da(s) cidade(s), o que nos parece algo auspicioso a uma reestruturação qualitativa do espaço urbano, especialmente no caso de São Paulo, foco maior de nossas preocupações. As derivas ao rés do chão nos permitiram aproximações importantes nesse sentindo, tanto na área central (Vale do Anhangabaú e imediações, por exemplo) como em espaços periféricos da metrópole paulistana (Campo Limpo, entre outros).

Essas práticas anunciariam, no conjunto, situações e possibilidades de uso e (re)apropriação de espaços na cidade.revelando certas conquistas e despertando o interesse de um número cada vez maior de pessoas, setores e segmentos da sociedade urbana. Ao lado de outras práticas, elas sinalizam para uma ampliação da experiência social e espacial do presente, que revoga a ideia de um presente reduzido, contraído e fugaz ante um futuro estendido, ambas as situações distorcidas por racionalidades míopes e indolentes, que deixam escapar ou não captam, adequada e suficientemente, "a riqueza inesgotável do mundo". (SANTOS, 2007)

Proceder a uma crítica radical da sociedade e da vida cotidiana não significa fazer dessa riqueza e diversidade uma espécie de tabula rasa ou realidade aplainada, homogeneizada por lógicas hegemônicas, quase que únicas e exclusivas, que não raro recaem em posturas interpretativas 
niilistas e distópicas. Engendradas no fulcro das contradições da vida cotidiana urbana, essas práticas entabulam o exercício da diferença, conformando outras e mais desejáveis ambiências urbanas, que sugerem modos variados e alternativos de usar o tempo e o espaço sob uma realidade que é estruturalmente impermanente.

Insistimos que, ao contrário do que frequentemente se supõe ou se afirma, elas não se projetam no intrincado cenário metropolitano como ocorrências marginais, frágeis ou desacreditadas, como expressões irrelevantes da sociedade e do social, portanto do próprio espaço. Não desprezando o cenário de adversidades e contradições recrudescidas relacionadas aos processos de apropriação e valorização econômica do espaço, que marca a vida em nossas sociedades e lugares, elas, pelo nosso ponto de vista, recomendariam maior atenção e cuidado analítico.

\section{Apropriação socioespacial e dialética da propriedade}

A objetivação socioterritorial dessas práticas suscita ou recoloca a dialética da propriedade em outros termos e planos, haja vista a propriedade poder assumir, pela apropriação, outros significados e atributos, com outras formas de valorização, não econômica ou não estritamente econômica, dando-se também como valorização afetiva, identitária e simbólica, inscrevendo-se, assim, na esfera do uso.

Ao mesmo tempo em que a apropriação encontra-se estreitamente vinculada à propriedade, sobretudo a propriedade privada, ela, a depender da forma como se dá seu uso social e das características que assume, a apropriação poderá, então, conferir novas qualidades à propriedade, ampliando-Ihe, até certo ponto, seu próprio significado, para além de sua função econômica. Não se quer dizer com isso que a função social da propriedade seja estabelecida necessariamente pela apropriação, que é conferida, principalmente, pelo seu uso econômico. Ademais, os atributos qualitativos que o uso social, no sentido da apropriação, pode conferir à propriedade também não quer dizer que ocorra a supressão do seu significado jurídico-formal, que está amparado e salvaguardado pelo estatuto da propriedade privada da terra. Daí a definição da função social da propriedade pelo próprio ordenamento jurídico, que reconhece que os poderes exercidos pelo proprietário não devem resguardar apenas a satisfação de seu interesse particular, conquanto o conceito de função social da propriedade envolva, apesar da prevalência do econômico, polêmicas, imprecisões e limites, esbarrando nas próprias contradições do processo socioespacial capitalista, que encontra no próprio agente regulador do Estado um dos seus pilares de 
sustentação e promoção, resguardando funções e interesses poderosos, ganhando preeminência os corporativos.

Dotada, assim, de certas qualificações e atributos - mais submetidos em nossa sociedade à troca e ao econômico -, a propriedade incorpora, por práticas de apropriação de espaços (ou de caráter apropriativo) outras funções e significados sociais e políticos, como se pode observar, por exemplo, em certos lugares de uso coletivo, que comportam expressivo significado público, tais como mercados municipais e galerias, como pudemos verificar, entre outros casos, no Mercado Municipal de São Paulo (mais conhecido como Mercadão), Galeria do Rock, Mercado Municipal de Belo Horizonte etc. Eles se definem, a princípio e de modo geral, como lugares de trocas comerciais, de compra e venda, mas também, e de modo não menos significativo, como espaços de uso coletivo compartilhado e de encontro, aspectos pelos quais eles são apropriados e dotados de outras funções e significados, conferindo-lhes, pelo uso, relações e ambiências de sociabilidade e trocas simbólicas, que não se restringem tão somente ao universo do consumo.

Essas práticas expressam certo consentimento à vida e ao gozo corporal que, em sua banalidade cotidiana, entram na estruturação do corpo social e suscitam o sentimento de pertencer, estabelecendo certos vínculos com o lugar. Desse modo, o sentido da propriedade torna-se mais elástico, com suas funções relativizadas pelo uso e pela apropriação. Apropriação de espaços que, pela nossa perspectiva, pode se realizar mediante ações deliberadas e/ou espontâneas sobre um dado lugar, por estímulos e demandas dos próprios interessados. Inscrevendo-se mais propriamente no plano do uso e do vivido, portanto também da política, ela recobre práticas espaciais e ambientais associadas a comportamentos exploratórios, que conferem ao lugar aspectos valorativos e funções que refletem certos interesses e necessidades que as deflagraram, compondo, assim, uma esfera situacional de maior proximidade e intimidade. Desse modo, ela não se confunde com a propriedade, e não necessária ou propriamente como expressão da superação da propriedade privada como forma e condição a emancipar totalmente todos os sentidos e qualidades humanos, tal como sugerido em Marx (1974, p.17), não obstante a ideia e o sentido dessa emancipação Ihes sejam inteiramente sensíveis e valorizados.

Remetemo-nos, desse modo, à condição de certa prevalência do espaço sobre a história, com o enraizamento nos lugares de grupos, tribos etc. tanto em tempo real como virtual, onde se criam territórios simbólicos igualmente partilhados, que não se reduzem em sua diversidade a meras expressões vazias e destituídas de outros sentidos que não o da estrita socialização pela mercadoria. Trata-se de pedaços de territórios ou lugares pelos quais o existir de um pressupõe a 
relação com o outro, e não como expressão estritamente individual, como frequentemente se postula, realçando, assim, uma condição de individualização no âmbito do social.

Essa trama relacional recobre ambientes diversos, tais como certos tipos de bairros e suas formas de vida cotidiana, enredadas em torno de especificidades sensíveis, como música, vida boêmia, comida e gastronomia, atividades artísticas, ritos religiosos, etc. Não raro, determinados lugares e formas urbanas nesses espaços podem adquirir algum destaque, projetando-se como espaços de catalisação social. Nesse sentido, o lugar se revela dotado de possibilidades de vínculos, para além, mas também, dos de caráter estritamente econômico. Justamente numa época em que tanto se proclama a (equivocada) ideia da desterritorialização, quando o que se vê - sobretudo a um plano mais molecular/intersticial da vida cotidiana - é exatamente o contrário, com a história transcorrendo pela prevalência do espaço, ou ainda pela insurgência dos corpos em espaços a serem compartilhados. Pode-se atribuir às chamadas "tribos pós-modernas" algo dessa natureza, que expressam conformações socioterritoriais sob o traço de certo "enraizamento". Enraizamento territorial que pode mostrar-se tanto real - o pequeno "cantão" em que vivemos - como virtual no âmbito dos novos meios de comunicação, que se dá em função de preferenciais sexuais, religiosas, musicais, constituindo territórios simbólicos que repousam sobre a mesma lógica de partilha, vinculação e "religação". (MAFFESOLI, 2007, p.68)

Portanto, estaríamos cada vez mais submetidos a um tempo que se espacializa, expondo uma reorganização contundente de desafios e questões postos pela espacialidade contemporânea.

Desenvolve-se, pois, um cenário irrequieto no qual se precipitam inúmeras ambiências espaciais, dando-nos um contexto de fractais, em que as relações e interações de conjunto e de grupo, em torno de necessidades e interesses comuns, se anunciam e se projetam por táticas variadas, politizando-se, assim, seus motivos e conteúdos, em que pese o suporte de meios e tecnologias de comunicação. Acresce, todavia, o cuidado de não confundi-las ou de tomá-las como expressões de mera espetacularização da vida cotidiana.

\section{Estado e revitalização urbana: implicações em espaços centrais}

Por contraste, temos que ao plano da gestão urbana, que afeta diretamente a dinâmica social e a vida das pessoas, a atuação do Estado técnico-burocrático se realiza como um empreendimento econômico-comercial, pela qual a cidade é, em grande medida, tratada como um negócio, sob uma perspectiva empresarial, administrada como "cidade-empresa" (ARANTES, 2000), tornando- 
se, sob esta condição, objeto de ações a que se torne competitiva, rentável, atrativa a novos investimentos.

Consubstanciada, portanto, em mercadoria, a cidade perde, então, a sua condição de obra, conceito pelo qual Lefebvre (1991) a reconhece como um lócus comum, no sentido de comunidade, como uma produção conjunta e compartilhada por seus membros e habitantes. $\mathrm{O}$ que vale dizer: as normas do mercado modelando tendencialmente as normas públicas, dandonos a ideia de que são os negócios que governam a cidade e não os governos. (SANTOS, 1999, p.15)

Nesse sentido, a atuação dos empresários urbanos torna-se proeminente e decisiva quanto à constituição e conformação da urbe, que conta com a anuência e o suporte do Estado, que, por meio das legislações urbanas, transforma o espaço em conformidade com os interesses das frações hegemônicas do capital, especialmente os capitais corporativos, consubstanciando o uso do espaço como instrumento de dominação econômica e política. Pela dominação econômica ele é convertido amplamente em uma mercadoria, uma base de geração de valor, orientado à busca permanente pelo lucro, desencadeando o redimensionamento ampliado e geograficamente estendido de desigualdades e segregações socioterritoriais. Pela dominação política, o Estado cristaliza essas diferenças, tendo nessa contradição uma estratégia, de modo a assegurar os interesses econômicos hegemônicos no espaço, a exemplo do que ocorre em espaços centrais, sob a ação estatal remodeladora. Ao mesmo tempo, essa condição pode conduzir ao enfraquecimento do poder dos seguimentos populares ante a ordem pública estatista. Isso se põe como uma contradição bastante incômoda, um grande desafio a ser equacionado pelo Estado, mas que não é um problema insolúvel.

Os espaços centrais das cidades readquirem enorme interesse às chamadas políticas de revitalização, que encontram na memória e na história urbanas novas frentes de valorização, pondo em evidência certa mercantilização da cultura ao plano da economia simbólica das cidades, que se projeta como campo de grandes interesses urbanísticos e inversões territoriais de grande impacto, tanto na estrutura como na vida urbanas. Eles definem efetivas políticas espaciais que se orientam preferencialmente a essas áreas, tendo no capital imobiliário o vetor fundamental dessas frentes de expansão e valorização.

No que afeta mais especificamente aos espaços centrais da cidade de São Paulo, marcados pela estagnação e deterioração urbanas, as políticas à reestruturação dessas áreas demarcam não apenas uma busca pela reocupação do centro, com interesses urbanísticos em torno da 
preservação de bens patrimoniais, como também traduzem uma busca por reaver ou reafirmar sua identidade cultural; o que não se verifica, contudo, apenas em São Paulo, mas em diversas outras cidades do Brasil e de um grande número de países que realizam políticas de revitalização de áreas centrais.

A prevalência de interesses hegemônico-empresariais no espaço urbano, que o consubstancia como mercadoria e ambiente privilegiado de grandes negócios se afirma a despeito de instruir e modelar a produção de uma espacialidade marcada por certo esvaziamento da coletividade, pela redução da solidariedade, avanço da impessoalidade e da indiferença, e da monotonia rotineira urbana, que instauram uma atmosfera compressiva na vida cotidiana. Segue-se daí a retração/supressão progressiva do espaço público (em franco declínio), ao mesmo passo que o desenvolvimento da espetacularização da vida - marcada pela alienação, passividade e insuficiência de participação, com as expectativas de vida apoiadas em solo instável e movediço, impondo a ela, e à existência, níveis cada vez maiores de apreensão e incerteza, angústia e insegurança.

Vislumbra-se, nesse sentido, um cenário marcado pelo domínio do medo e da insegurança, no qual as cidades assistem à proliferação de verdadeiras estruturas autistas, fortalezas defensivas, vigiadas e controladas a separar ou segregar os desiguais e suas diferenças, e as próprias pessoas, que assim vão se tornando progressivamente acuadas e deixando de se reconhecer no espaço em que vivem, descolando-se dele sob os efeitos de uma lógica devotada à competitividade, ao consumo desenfreado e a privatização da vida, sob a incidência do tédio e estratégias de fuga; drogas diversas proliferam.

A rua, nesse contexto, vem se transformando de morada do coletivo em via de fluxos e de passagem, perdendo sensivelmente sua condição histórica de promoção do encontro e da sociabilidade, conquanto esta condição ainda não se mostre absoluta, havendo manifestações sociais insurgentes a ela, e até mesmo ações de governos orientadas à sua revitalização e a usos sociais, embora essas ações possam desencadear a valorização econômica de espaços no entorno dela, atraindo novos investimentos, o que, no entanto, não suprime a intencionalidade e a objetivação da ação.

Em larga medida, e com maior contundência nas grandes cidades - a exemplo do que se verifica na cidade de São Paulo -, as vias de circulação estão submetidas progressivamente ao automóvel, dominadas por ele, sob constrangimentos constantes, do que já se tornou prepotência motorizada. 
Essa situação, que integra uma tendência mortificante da cidade, destrói progressivamente espaços públicos (como praças, calçadas e a própria rua), recrudescendo-se substantivamente no Brasil nas duas últimas décadas, sobretudo, com um crescimento vertiginoso da venda de automóveis e motocicletas, em detrimento do uso do transporte público nas maiores cidades. Tão evidente quanto o brilho do sol, que, essa condição mortificante irradia-se de forma perturbadora pelas cidades, mantendo estreitas relações com políticas de desenvolvimento econômicoindustrial conduzidas pelo Estado (ainda desenvolvimentista). Operando reiteradamente sob a lógica estreita do crescimento econômico, sob o manto ideológico da sustentabilidade, ele praticamente passa ao largo de implicações urbanísticas e socioambientais absolutamente nefastas que o urbanismo rodoviarista produz.

Pressionando a cidade e a vida urbana em diversos aspectos, todos eles problemáticos, há efeitos compressivos substanciais no uso de espaços (sobretudo espaços abertos de uso coletivo) na cidade, abertamente submetida a uma motorização ensandecida. Pelo incremento do transporte individual e familiar, a motorização automobilística em curso assume contornos de pleno descontrole, inscrevendo-se no fulcro de uma urbanização degradante consentida, quer seja pelo Estado, quer por boa parte da própria sociedade, que vê no automóvel uma das principais condições, se não o instrumento maior, de projeção e status social. Daí poder-se dizer que ao plano das mediações entre as pessoas e o espaço urbano, o automóvel comparece hoje como uma das mais importantes. Recobrindo todo o espaço, o automóvel e, mais especificamente, o problema da mobilidade urbana que ele passou a representar (dado seu uso exponencial e ampliado), se anuncia como um dos maiores desafios do urbanismo contemporâneo. 0 decorrente declínio do caminhar e da fruição paisagística, ante uma cidade concebida e construída para o automóvel, comparecem como expressões incômodas da alienação socioespacial de nossos tempos, ao mesmo tempo em que opera como um de seus principais condicionantes. Ações coletivas como as conduzidas por movimentos de ciclistas na cidade anunciam e imprimem maior politização em torno de demandas por uma forma mais saudável e eficaz de mobilidade e uso social de lugares diversos da cidade. Práticas artístico-culturais em trechos de ruas ou espaços abertos como praças vão também nessa mesma direção, pondo-se como demandas sociais ao mesmo tempo em que sinalizam para outras formas de uso social de lugares da cidade. Grosso modo, pode-se dizer que essas práticas, no seu conjunto, expressam uma forma de luta pelo uso social e pelo direito à cidade, que sabidamente vive compressões permanentes à vida e em seus aspectos qualitativos. 
A rua, nesse sentido, contém a inerência de um uso estreitamente vinculado à vida das pessoas na cidade, sendo praticamente impossível pensar a humanização das cidades dissociando-a de um efetivo sistema de pedestres, e nele o importante papel desempenhado pelas calçadas, as quais, em larga medida, imprimem maior vitalidade aos ambientes urbanos. Apenas para que se tenha uma ideia da situação das calçadas na cidade de São Paulo, dados de 2012 apontam que elas compreendem uma extensão da ordem de $30 \mathrm{mil} \mathrm{km}$, estando boa parte delas em condições bastante precárias, com irregularidades diversas, tais como raízes de árvores quebrando suas superfícies, canteiros mal feitos e mal posicionados - prejudicando a circulação de pedestres -, revestimentos sofríveis etc.. Apenas uma parte menor se apresenta em bom estado de conservação, em alguns pontos da cidade, parcialmente reformadas e melhoradas. Nos extremos da periferia da metrópole a qualidade do calçamento mostra-se, de modo geral, em condições deploráveis, e em muitas áreas ele se quer existe. De acordo com pesquisa realizada pelo Datafolha (Folha de São Paulo), realizada em julho de 2012, o mau estado dos passeios públicos é para os paulistanos um dos dez maiores problemas da cidade. (GONÇALVES, 2012, p.C2)

Assim, a rua se constitui tanto em via de fluxos como em espaço de uso e de apropriação pelos citadinos - aspecto que modernamente experimenta substancial redução, mas não propriamente sua supressão por completo. Posto que a rua também encerre funções simbólicas, comunicacionais e lúdicas, ela possibilita interações variadas e o contato com as diferenças, o que nem sempre se dá pelo viés do convívio democrático, mas inclusive. Elas podem se conformar por práticas socialmente apropriativas, desempenhado assim funções socioterritoriais importantes à vida urbana, tais como sociabilidade (inseparável da individualidade, integrada à multiplicidade), lazer, atividades culturais, políticas etc. Ainda que se mostrem significativas, elas também o são hoje bastante abstratas; contudo, parte expressiva delas ainda se realiza "face a face", o que mantém a possibilidade da emergência do genuinamente novo que desejamos no espaço, nós e todos aqueles que apostam na vida (plena) antes de todas as coisas.

Até mesmo a espontaneidade do encontro e do fluir pelo espaço e pelo tempo sem programação, sofrem, sob as interferências da evolução do momento e dos ritmos acelerados da vida cotidiana, certa redefinição, incorporando-se, assim, à programação, passando, portanto, a ser uma ação consciente, mas que, apesar das restrições impostas pela racionalidade do trabalho e do tempo da mercadoria e do lucro, escapam-Ihes, como que em movimentos de pulsão liberatória das amarras e compressões cotidianamente impostas; a variável aleatória, que irrompe sob a forma de uma necessidade existencial, que ainda retém o momento mágico inerente à vida humana. Ela se 
objetiva no espaço e no tempo sob o sentido do uso, que pode anunciar algo além do que está posto, chocando-se com estereótipos existentes e perturbando o andamento formal das coisas e do plano. No percurso, pequenas rupturas intersticiais e novas determinações no espaço movente poderão mesmo acontecer, delineando cenários possíveis e descontínuos de usos apropriativos de lugares.

Não se quer com isso sugerir um movimento orientado a uma ampla ruptura com a lógica socioespacial hegemônica, mas sinalizar para uma dimensão insurrecional do uso na urbanização extensiva contemporânea, que anuncia a vida e o vivido no interior da experiência, abrindo perspectivas mais desafiadoras nas abordagens do espaço e da espacialidade hodiernas, imprimindo-lhes, nesse sentido, maior potencial político. O que vale dizer que os espaços e os lugares mostram-se como expressões abertas, múltiplas e relacionais, não acabadas e postas em movimento e em perspectiva, sensíveis não apenas ao que está neles, mas também ao que se anuncia. Nesse sentido a própria história apresenta-se em aberto, como um horizonte de possibilidades da política. (MASSEY 2008)

Embora recaia sobre o espaço e a rua estratégias de dominação e controle, através do planejamento e do urbanismo, a rua, bem entendido, não se reduz a essa condição, posto que o mesmo aparelho estatal também atue na criação de condições e infraestruturas devotadas ao desenvolvimento de recuperação de áreas públicas e a melhoria dos padrões socioambientais, entre outros aspectos, que reverberam na vida pública da cidade. Não se quer dizer com isso que o Estado tenha alcançado ou se situe em níveis adequados na promoção do uso social da cidade. Todavia, postular que suas ações representem ou conduzam invariavelmente à mortificação progressiva do espaço e da vida na cidade, nos parece uma interpretação genérica, fazendo-se uma espécie de tabula rasa do universo de casos e situações, sobretudo no que afeta à inserção e participação popular na formulação de políticas públicas, as quais, sob essa perspectiva, são desacreditadas em seus propósitos e alcance.

A vertente democrático-participativa (que sempre solicita ajustes e aprimoramentos permanentes) sinaliza, ao contrário, avanços auspiciosos quanto à qualidade e aos objetivos das ações e políticas públicas, de modo a que demandas sociais legítimas possam ser submetidas a um maior controle social, interferindo-se mais diretamente no que afeta à vida das pessoas, o que evidentemente não se dá sem dificuldades e embates permanentes entre as forças e interesses envolvidos. 
Considerem-se, ainda, outros vetores de organização e ação política, que operam de forma mais independente do Estado, e, em determinadas circunstâncias, associadamente a ele, como bem o demonstram práticas de cogestão, tais como na área de moradia popular, entre outras etc.. Isso não significa, entretanto, uma espécie de defesa incondicional do Estado e do estatismo. Ponderase que nem sempre ou necessariamente ações e formas de atuação do Estado, sob uma perspectiva efetivamente mais democrática e transparente de determinados governos, sejam condenáveis ou invariavelmente nefastas, social e territorialmente, conquanto o Estado retenha uma condição contraditória e ambígua, posicionando-se tanto na defesa dos interesses corporativos do capital e do mercado, como das questões e demandas sociais. Ou ainda, através do planejamento urbano e do ordenamento territorial o Estado cria e conforma espaços de dominação e controle, fazendo prevalecer suas intencionalidades subjacentes, ora se posicionando em contradição e conflito com os interesses específicos da reprodução do capital no espaço, ora colocando-se junto a eles em sua promoção. (CARLOS, 2001)

\section{O ponto de inflexão: limites, emergências e aberturas}

Nesse sentido, pode-se dizer que o Estado se encontra, sobretudo nos tempos atuais, numa encruzilhada entre o mercado e a democracia. Todavia, põe-se em consideração que governos operam sob restrições objetivas, e que certas limitações à execução de empreendimentos socialmente demandados podem ser interpretadas como inoperância intencional ou subserviência a interesses corporativos. Isso sinalizaria para uma postura de maior flexibilidade na avaliação de condições e limites sob os quais os governos atuam. Do mesmo modo, isso não significa soçobrar a distorções políticas efetivamente danosas e inaceitáveis ao território e à sociedade.

Não obstante o cenário de contradições e desigualdades que marcam a espacialidade brasileira e, mais especificamente, a paulistana - sobre as quais incide historicamente uma substancial presença diretiva estatal -, não seria totalmente verdadeira a afirmação de que sob a atuação do Estado a vida nos lugares e, mais especificamente, nas ruas e em outros espaços de uso coletivo tenha sido praticamente banida, ou ainda que ela tenha se tornado uma miríade de expressões de uma anti-vida, inteiramente absorvida pelo consumo e pelo espetáculo do consumo, dominada 
pela alienação social - conquanto se reconheça que o avanço e a disseminação destas constituam uma realidade inequívoca.

Alertamos, com isso, para o problema representado pelas generalizações, as quais, com certa freqüência, tomam lugares e ruas como espaços mortos, esvaziados de vida e de relações sociais qualitativamente significativas, reduzidos a espaços tão somente de realização de demandas do capital, condição que supostamente interditaria ou inviabilizaria o encontro e a sociabilidade, os quais, não raro, aparecem como funcionais ao capital e ao mercado. Embora também o sejam, eles não se revelariam, por nossa compreensão, tão residuais como normalmente se pensa.

Portanto, não se trata de forjar situações ou mesmo negar a veracidade de uma ambiência expansiva da alienação e seus efeitos corrosivos na vida social e, desse modo, nos territórios, havendo razões e evidências à mão cheia que os comprovam. Tais aspectos, aliás, reputamos figurar, por uma lente mais fina, na arena dos dilemas urbanos e seus grandes desafios.

Não menos importante do que tomá-los em devida conta, é proceder pela lógica da atenção, que valoriza o conhecimento dos lugares e situações correlatas por meio do passo, revogando-se, nesse sentido, leituras pelo alto, que levam quase que invariavelmente o sentido da perda e da degradação no âmbito do político e do social, logo do socioterritorial, obscurecendo e esvaindo expressões sociais e modos territoriais de vivência valorativos.

Incorre-se, desse modo, em certa redução do urbano e da vida cotidiana. Nessa perspectiva é importante distinguir quando a mercadoria opera como mediação relacional e quando ela só comparece como um recurso ou instrumento na relação social, ainda que sob o capitalismo em sua fase atual a mediação pela mercadoria tenha se tornado proeminente e generalizada, pesando para isso a publicidade ostensiva do consumo, que cria e introduz nas mentes valores e representações, instaurando, assim, uma cultura, portanto um modo de vida. Todavia, os homens não entram em contato tão somente por intermédio do mercado, da mercadoria e dos mercadores, ainda que sob as economias mercantis o fetichismo possa ser considerado algo que Ihes seja inerente; inerência que não é, contudo, algo absoluto ou exclusivo.

Consideramos que ainda assim há vida pulsante em diversos lugares e ruas da cidade, na metrópole paulistana, aqui incluído o centro antigo, com bares e botequins fervilhantes, com movimentos que se estendem por calçadas e praças, além de diversas galerias e outras formas urbanas que atraem pessoas de segmentos sociais variados, suscitando certa aglomeração social, ambientes de burburinho e interação social. Elas apontam, pela nossa interpretação, para outras e mais desejáveis situações de vida e uso de espaços na cidade, conferindo-lhes caracteres de usos 
conexos ao sistema de valores dos grupos sociais que neles vivem e operam. Nesse sentido, podese dizer que o uso compartilhado de lugares irrompe no cotidiano urbano sob demandas da existência e da relacionalidade que recobrem comportamentos e hábitos dotados de certo traço apropriativo de espaços, incluindo-se aqui ruas e trechos, não se mostrando, assim, tão pouco expressivas ou de baixa incidência.

Por contraste, há evidências claras e inequívocas nessas áreas de certa deterioração da vida pública, que revelam uma cornucópia de dados e expressões terrificantes da realidade urbana, como o demonstram, por exemplo, a proliferação de cracolândias, não apenas em áreas abertas ou pontos escondidos sob viadutos e pontes, mas também em hotéis baratos e cortiços.

Situações mais desejáveis de vida guardam certa importância em termos de possíveis mudanças e transformações dos padrões ordinários da vida e do viver em nossas cidades. E, embora não se possa falar aqui de uma apropriação absoluta de lugares e das condições pelas quais eles foram concebidos e produzidos, estas práticas e/ou modalidades de apropriação talvez pudessem ser mais bem qualificadas, de modo geral, como de apropriação relativa, embora também possam se realizar de forma mais efetiva, com uma maior identidade e reconhecimento ao plano do fazer, entre o sujeito e o produto de seu trabalho - não necessariamente remunerado -, de modo a conferir maior sentido e razão à sua vida e existência. Assim, elas não revelariam propriamente um "mundo apropriado", se é mesmo possível ou factível admitir-se a apropriação a essa escala ou dimensão, mas revelariam apropriações possíveis, que envolve embates. Ainda assim elas são auspiciosas na vida da metrópole, forjando ambiências aos reclamos da existência, conformando esferas societárias mais íntimas.

Daí poder-se falar de uma relativa, e possível, desalienação para com o espaço (e o lugar) - o que não significa tomá-la como tendência, mas como possibilidade factível -, considerando-se que a plena superação ou alternativa à alienação se mostra sempre, ou quase sempre, como algo relativo, posto ser ela inerente às relações sociais e à condição humana, sobretudo sob a lógica do sistema produtor de mercadorias. Portanto, isso não significa que estejamos diante de atores sociais "religados" ao produto do seu trabalho, como que reassumindo o seu pleno controle, o que implicaria o do próprio espaço. Mas, ainda assim, conferimos relevância política a experiências socioespaciais livres e experimentais, que incluem práticas auto-organizacionais, uma vez que podem entabular usos inventivos nos lugares, capazes de confrontar ou mesmo subverter condições indesejáveis de vida, forjando-se, assim, uma espécie de razão de viver, buscando-se, por ações e ambiências mais desejáveis, dar vazão a impulsos criadores, aspectos importantes ao 
alcance de um maior sentido de realização pessoal. Essa possibilidade está virtualmente presente em diversas práticas sociais, que buscam caminhos outros, alternativos, reagindo às compressões do cotidiano, à escalada vertiginosa do consumo e dos constrangimentos que exerce na vida prática de cada um. A idéia do trabalho como esfera de autorrealização humana parece estar se distanciando cada vez mais em meio a intensificação tecnológica e a mercantilização das relações sociais. Mas negar ou mesmo diminuir a existência de práticas que operam outros sentidos e outras lógicas, é fazer tabula rasa do processo social, como se a história terminasse aqui.

Essas experiências vão, pouco a pouco, compondo um cenário socioespacial mais lúdico e interativo, que amolda outras ambiências ao lugar, delineando contrapontos intersticiais ao ciclo rotineiro do trabalho, favorecendo pequenas rupturas em relação à lógica mortificante da racionalidade urbana, distanciando-se, de certo modo, da redoma espaço-temporal do trabalho coercitivo. Elas respondem por outros usos do tempo, outros modos de vivenciar os lugares, mais sintonizados com as liberdades e sensibilidades humanas. Distanciadas de uma condição passiva, elas nos sugerem, ao contrário, a idéia de situações ou de "palcos dinâmicos", com modulações socialmente influenciadoras mais bem identificadas com os desejos humanos. Não compartilhamos da idéia de que sejam expressões de uma vida estritamente privatizada, fechada a um dado segmento social que pode pagar por ela, assumindo os seus custos. Em parte, apenas, isso se mostra verdadeiro.

O centro antigo permanece uma expressão viva na vida e na memória de São Paulo; ele ainda inspira e faz recriar imagens e representações da cidade, que célere e intensamente se transformou, respondendo por problemas diversos, tais como os relativos aos espaços públicos e edifícios patrimoniais. No entanto, tais problemas não se mostram irreversíveis e sem solução, contribuindo para essa possibilidade as próprias capacidades da cidade.

Com a presença de segmentos sociais variados, ele comporta uma diversidade de lugares que se mostram como territórios de sociabilidade aberta, em que pesem a atratividade de sua localização, a qualidade dos serviços e produtos oferecidos, a ambiência social diversificada, a força da tradição de parte desses pontos, entre outros aspectos. Eles se dão como determinações do próprio lugar, por aquilo que lhes é imanente ou histórica e socialmente adquirido, guardando, nesse sentido, estreitas relações com o uso e o valor de uso, escapando ou desviando-se, de certo modo, dos limites representados pela propriedade, em seu sentido econômico e jurídico. Eles projetam formas de uso de espaços tanto mais duradouras como circunstanciais, efêmeras ou moventes, que recobrem ou conotam a apropriação sob modulações múltiplas, que não se 
reduzem (e não deveriam ser confundidas) a uma espécie de alienação coletiva espetacularizada. Em suas formas mais incisivas, perturbam e negam racionalidades dissociativas, produzidas pelo urbanismo gerencial, que instaura o sentido da anti-cidade. Acerca desta temos o que poderíamos qualificar de engenharia urbanística da estupidez, que nega, em essência, condições favoráveis à vida da maioria, ao mesmo tempo em que irriga os negócios fundiário-financeiros de uma acumulação privada corporativa.

Não por acaso irrompem práticas e ações diversas pelos interstícios da metrópole, que lhes imprimem revitalização social, política e cultural, sugerindo-nos trajetórias alternativas à condição de mortificação do espaço, dando visibilidade a demandas sociais e a problemas relativos à anticidade.

A proeminência do uso do automóvel, mais particularmente no que afeta à metrópole paulistana, comparece indubitavelmente como um dos principais fatores na redução e na interceptação da apropriação social de seus espaços, associando-se a este a valorização econômica da terra e os processos especulativos. Porém, não seria correto afirmar que o automóvel tenha sido o "grande vilão" do esvaziamento da importância do centro antigo; podendo-se afirmar, isso sim, que ele foi uma de suas principais causas, acarretando a implantação de grandes sistemas viários de circulação na cidade, pressionando continuadamente o espaço físico ao alargamento de vias públicas, subtraindo aos pedestres os espaços das caçadas (estreitando o espaço urbano a seus habitantes), criando a necessidade de vias expressas (alargando o espaço urbano aos automóveis), as quais mutilaram e destruíram, no curso de sua construção, "partes significativas da memória e das paisagens urbanas" da cidade e de sua área central. (SCARLATO, 2010, p.263).

Todavia, há que se ter certa cautela na análise das transformações ocorridas no centro antigo, bastando lembrar que elas não significaram nem um esvaziamento amplo de todas as suas atividades importantes - as quais, em parte continuam existindo ali, concentrando atividades comerciais e serviços fundamentais -, nem representaram uma espécie de sucateamento de seu prestígio, guardando "de forma latente os elementos construtivos e simbólicos de sua identidade e de sua vitalidade". (SCARLATO, 2005, p.134)

A restituição ou incremento do uso de espaços implica necessariamente uma reorientação do uso do automóvel nas cidades. São Paulo efetivamente se transformou num verdadeiro inferno motorizado. O cenário constrangedor da mobilidade urbana na metrópole paulistana impõe inúmeros problemas à vida na cidade, impactando e restringindo enormemente o uso coletivo e individual de espaços na cidade. 
Não obstante, ações orientadas à retração do uso generalizado do automóvel na cidade não bastariam, por si mesmas, para resolver a situação de degenerescência de espaços e da qualidade de vida nesta e em outras cidades, posto não serem suficientes para resolver ou melhorar, mais a fundo, o problema da pobreza urbana. Isso demandaria um conjunto de outras ações ao plano do desenvolvimento social e da economia urbana. E ainda que estas fossem bem sucedidas, não debelariam por completo o problema; na melhor das hipóteses ele seria reduzido em suas manifestações, mas não plenamente resolvido, posto ser a pobreza um problema estrutural dessa economia. Entretanto, essas ações, se bem conduzidas e submetidas a controle social, podem estimular ou favorecer o uso coletivo e mais democrático de espaços na cidade, que enfrenta, como muitas outras, o declínio notório da vida pública, bem como do caminhar (prática criadora de ambiências, encontro e socialização) e a degradação de lugares e de condições de vida, não obstante reverberando na própria vida privada, que sob essa condição também é afetada. A motorização da sociedade é flagrante e nossas cidades se debatem com a sua generalização, sendo esse um aspecto que, no nosso entender, é crucial na problematização mais atual do uso e da apropriação do espaço urbano.

Essa situação, ademais, também comporta um problema de saúde pública, que afeta negativamente, e de variadas maneiras, lugares e pessoas, perturbando e deteriorando relações sociais (agindo, inclusive, sobre a dinâmica dos sentimentos e emoções), portanto também para com o espaço. Daí poder-se dizer que essa condição alimenta a própria alienação social e territorial, impondo desafios de monta a quaisquer políticas urbanas e outras práticas e iniciativas que aspirem em seus propósitos uma (outra) condição territorial-urbana.

\section{CONSIDERAÇÕES FINAIS}

Essa busca por condições socioterritoriais mais desejáveis implica, portanto, atos práticos interventivos e propositivos na vida cotidiana, que operam como forças integrativas na rearticulação entre as pessoas, suas ações e o produto delas. Isso significa um movimento de transição/transformação (de certo modo inesgotável) de uma condição alienadora para outra condição pautada e constituída por práxis cotidianas, despojadas, em seu sentido e significado, tanto de pressuposições abstratas acerca da unidade sociedade e espaço, como de um eventual caráter estritamente utilitarista que comumente se infere do significado do vocábulo "prático" na linguagem ordinária, conquanto a práxis designe uma atividade humana consciente que produz 
objetos e materialidades ("atividade material do homem social") (SÁNCHEZ VÁSQUEZ, 1968), portanto, envolvendo também a própria produção e conformação do território e da paisagem. Ou seja, a práxis não apenas comporta em seu sentido uma dimensão histórica e social como também espacial ou territorial, que são, em realidade, indissociáveis, formando uma unidade. Sua objetivação nos lugares e interstícios, onde o drama social efetivamente se desenrola e adquire concretude, mostra-se, assim, indissociável da apropriação. Daí poder-se dizer que a apropriação representa o limite (que não é absoluto) à alienação, comportando potencialidades à sua possível reversão, não obstante esta possa também se dar de forma relativa ou parcial sob a proeminência da racionalidade capitalista.

Assim, o embate a uma possível superação dessa condição envolveria, por conseguinte, ações e estratégias nos diversos campos da vida social, da cultura, da economia e da política, inseparáveis da totalidade socioespacial. No que concerne ao uso e a apropriação de lugares (e interstícios), é necessário, pois, valorizar a dimensão afetiva e subjetiva dos atores sociais, possíveis vínculos topofílicos, relações de pertencimento, entre outros aspectos valorativos à realização da apropriação de espaços. Usos exploratórios e sistemáticos por deambulações, flaneries e derivas podem suscitar cartografias afetivas de ambiências urbanas. Em termos situacionistas isso se traduziria como uma "psicogeografia", que se orienta ao "estudo dos efeitos precisos do meio geográfico, conscientemente organizado ou não, agindo diretamente sobre o comportamento afetivo dos indivíduos". (IS, 1958, p.13, tradução livre). Mas de forma a não se restringir ao plano mental do sujeito, mas sendo capaz de objetivar-se como uma força prática, devotando-se, assim, à construção de novas situações geográficas, como expressões e modos de vida urbanos. Portanto, ela recobriria um caráter investigativo e propositivo.

Sob o culto obsessivo do consumo e do imediatismo automático são produzidas situações de dissociação relacional e banalização, ao mesmo tempo, e contraditoriamente, ações insurgentes e práticas de caráter reativo, que sugerem não apenas certa resistência aos impactos degradantes da globalização capitalista (sobre o pensamento, a política e a vida, portanto sobre o território), mas também descontinuidades aos moldes espaciais hegemônicos, com virtualidades a formas de vida mais intensas, mais ricas em diversidade, capazes de se organizar e evoluir sob a influência e a interferência direta dos próprios interessados. E, ousamos dizer, só assim o espaço será aceitável. E isso não é uma questão de gosto ou de preferência, mas de necessidade imperativa de sobrevivência e existência, com um maior interesse na cooperação qualitativa e em formas relacionais mais refratárias à alienação socioespacial cotidiana. Apesar da força e da dinâmica dos 
constrangimentos, tempo e espaço, indissociáveis, ainda permanecem em aberto, sobretudo pelos interstícios, pondo em relevo a questão premente de nosso viver socialmente compartilhado e, de forma associada, dos modos como as pessoas, na sua heterogeneidade, vivem e experimentam cotidianamente a cidade.

Assim, a vida, ainda que constrangida pela compressão cotidiana, responde, sensivelmente, por meio de buscas (que perquire também outros pensamentos, portanto outras perspectivas e outros modos de agir), tentativas e práticas experimentais que possam torná-la mais habitável e melhorada em dignidade, quer seja por meio de ações negociadas à produção de novos arranjos territoriais, quer por apropriações (provisórias ou não) que instauram novos usos e novos significados aos lugares. No conjunto, elas conformariam um movimento cotidiano descontínuo, que politiza o problema do uso e da apropriação social de espaços na cidade, trazendo à tona questionamentos acerca de limites e possibilidades a outras e mais desejáveis espacialidades do viver. Pode-se aduzir, nesse sentido, que essa questão está alçada hoje ao plano das necessidades fundamentais da vida e da existência na metrópole, que então se fragmenta, se estende e se torna uma realidade complexa e multiforme. Os corpos e mentes, que se devotam a essa questão socioespacial crucial de nossos tempos, não estão errando por caminhos quiméricos, mas forjando, teórica e praticamente, no espaço-tempo presente possibilidades e condições a formas mais intensas e melhoradas de vida.

\section{REFERÊNCIAS BIBLIOGRÁFICAS}

ARANTES, Otília. Uma estratégia fatal: a cultura nas novas gestões urbanas. In: Arantes, Otília et al. (org.). A cidade do pensamento único: desmanchando consensos. $2^{a}$. edição. Petrópolis: Vozes, 2000. p.11-74.

CARLOS, Ana Fani A. Espaço-tempo na metrópole. São Paulo: Contexto, 2001.

BLOCH, Ernst. $O$ princípio esperança. Trad. Nélio Schneider, Werner Fucks. Rio de Janeiro, Contraponto, 2005 [1959].

GONÇALVES, Marcos A. Calçadas infames. Folha de São Paulo, 01 de outubro de 2012, Cotidiano, p.C2. 
JONAS, Hans. O princípio responsabilidade: ensaio de uma ética para a civilização tecnológica. Rio de Janeiro: Contraponto/Editora PUC-Rio, 2006.

LEFEBVRE, Henri. A vida cotidiana no mundo moderno. São Paulo: Ática, 1991.

MAFFESOLI, Michel. O ritmo da vida: variações sobre o imaginário pós-moderno. São Paulo: Record, 2007.

MARX, Karl. Manuscritos econômico-filosóficos. São Paulo: Abril Cultural, 1974. (Coleção "Os Pensadores").

MASSEY, Doreen. Pelo espaço: uma nova política da espacialidade. Rio de Janeiro: Bertrand Brasil, 2008.

SÁNCHEZ VÁSQUEZ, Adolfo. Filosofia da práxis. Rio de Janeiro: Paz e Terra, 1968.

SANTOS, Boaventura de S. A sociologia das ausências e a sociologia das emergências: para uma ecologia dos saberes. In: Renovar a teoria crítica e reinventar a emancipação social. São Paulo: Boitempo, 2007. p.17-49.

SANTOS, Milton. Modo de produção técnico-científico e diferenciação espacial. Território, LAGET, UFRJ, ano IV, n.6 (jan/jun - 1999), Rio de Janeiro, 1999, p.5-20.

SCARLATO, Francisco C. Busca do centro: o reencontro com a cidade. In: Carlos, Ana F. A.; Oliveira, Ariovaldo U. de. (orgs). Geografias de São Paulo: representação e crise da metrópole. São Paulo: Contexto, 2010. p.247-270.

SCARLATO, Francisco C.. Revitalização do centro antigo: o espaço da memória de São Paulo. In: Carlos, Ana F. A.; Carreras, Carles. (orgs). Urbanização e mundialização: estudos sobre a metrópole. São Paulo: Contexto, 2005. p.130-136.

Artigo submetido em: 16/04/2014

Artigo aceito em: 17/09/2014 